\title{
Phase transition observations and discrimination of small cloud particles by light polarization in expansion chamber experiments
}

\author{
Leonid Nichman ${ }^{1}$, Claudia Fuchs ${ }^{2}$, Emma Järvinen $^{3}$, Karoliina Ignatius $^{4}$, Niko Florian Höppel ${ }^{3}$, Antonio Dias ${ }^{5}$, \\ Martin Heinritzi ${ }^{6}$, Mario Simon ${ }^{6}$, Jasmin Tröstl ${ }^{2}$, Andrea Christine Wagner ${ }^{6}$, Robert Wagner ${ }^{7}$, \\ Christina Williamson ${ }^{6, \mathrm{a}, \mathrm{b}}$, Chao Yan $^{7}$, Paul James Connolly ${ }^{1}$, James Robert Dorsey ${ }^{1,8}$, Jonathan Duplissy ${ }^{9}$, \\ Sebastian Ehrhart $^{5}$, Carla Frege ${ }^{2}$, Hamish Gordon ${ }^{5}$, Christopher Robert Hoyle ${ }^{2,10}$, Thomas Bjerring Kristensen ${ }^{4}$, \\ Gerhard Steiner $^{7,11, \mathrm{c}}$, Neil McPherson Donahue ${ }^{12}$, Richard Flagan ${ }^{13}$, Martin William Gallagher ${ }^{1}$, Jasper Kirkby ${ }^{5,6}$, \\ Ottmar Möhler $^{3}$, Harald Saathoff ${ }^{3}$, Martin Schnaiter ${ }^{3}$, Frank Stratmann ${ }^{4}$, and António Tomé ${ }^{14}$ \\ ${ }^{1}$ School of Earth, Atmospheric and Environmental Sciences, University of Manchester, Manchester, M13 9PL, UK \\ ${ }^{2}$ Laboratory of Atmospheric Chemistry, Paul Scherrer Institut, 5232 Villigen, Switzerland \\ ${ }^{3}$ Karlsruhe Institute of Technology, Karlsruhe, Germany \\ ${ }^{4}$ Institute for Tropospheric Research (TROPOS), 04318 Leipzig, Germany \\ ${ }^{5}$ PH Department, CERN, Geneva, Switzerland \\ ${ }^{6}$ Institute for Atmospheric and Environmental Sciences, Goethe-University Frankfurt, Frankfurt am Main, Germany \\ ${ }^{7}$ Department of Physics, University of Helsinki, P.O. Box 64, 00014 University of Helsinki, Helsinki, Finland \\ ${ }^{8}$ National Centre for Atmospheric Science, Manchester, UK \\ ${ }^{9}$ Helsinki Institute of Physics, Helsinki, Finland \\ ${ }^{10}$ WSL Institute for Snow and Avalanche Research SLF Davos, Davos, Switzerland \\ ${ }^{11}$ Ion Molecule Reactions \& Environmental Physics Institute of Ion Physics and Applied Physics Leopold-Franzens \\ University, Innsbruck, Austria \\ ${ }^{12}$ Centre for Atmospheric Particle Studies, Carnegie Mellon University, Pittsburgh, PA 15213, USA \\ ${ }^{13}$ Division of Chemistry and Chemical Engineering, California Institute of Technology, Pasadena, CA, 91125, USA \\ ${ }^{14}$ CENTRA-SIM, University of Lisbon and University of Beira Interior, 1749-016 Lisbon, Portugal \\ ${ }^{a}$ now at: Chemical Sciences Division NOAA Earth System Research Laboratory, Boulder, CO, USA \\ balso at: Cooperative Institute for Research in Environmental Sciences, University of Colorado Boulder, \\ Boulder, CO, USA \\ ${ }^{c}$ now at: Aerosol Physics and Environmental Physics Faculty of Physics, University of Vienna, Vienna, Austria
}

Correspondence to: Leonid Nichman (leonid.nichman@manchester.ac.uk)

Received: 18 September 2015 - Published in Atmos. Chem. Phys. Discuss.: 10 November 2015

Revised: 3 March 2016 - Accepted: 3 March 2016 - Published: 17 March 2016

\begin{abstract}
Cloud microphysical processes involving the ice phase in tropospheric clouds are among the major uncertainties in cloud formation, weather, and general circulation models. The detection of aerosol particles, liquid droplets, and ice crystals, especially in the small cloud particle-size range below $50 \mu \mathrm{m}$, remains challenging in mixed phase, often unstable environments. The Cloud Aerosol Spectrometer with Polarization (CASPOL) is an airborne instrument that has the ability to detect such small cloud particles and measure the variability in polarization state of their backscat-
\end{abstract}

tered light. Here we operate the versatile Cosmics Leaving OUtdoor Droplets (CLOUD) chamber facility at the European Organization for Nuclear Research (CERN) to produce controlled mixed phase and other clouds by adiabatic expansions in an ultraclean environment, and use the CASPOL to discriminate between different aerosols, water, and ice particles. In this paper, optical property measurements of mixedphase clouds and viscous secondary organic aerosol (SOA) are presented. We report observations of significant liquidviscous SOA particle polarization transitions under dry con- 
ditions using CASPOL. Cluster analysis techniques were subsequently used to classify different types of particles according to their polarization ratios during phase transition. A classification map is presented for water droplets, organic aerosol (e.g., SOA and oxalic acid), crystalline substances such as ammonium sulfate, and volcanic ash. Finally, we discuss the benefits and limitations of this classification approach for atmospherically relevant concentrations and mixtures with respect to the CLOUD 8-9 campaigns and its potential contribution to tropical troposphere layer analysis.

\section{Introduction}

Scattering and absorption due to atmospheric particles can vary widely, leading to a net radiative effect that either cools or warms the surface of the Earth. Ice crystals pose a potential challenge since their non-sphericity complicates the theoretical description of their single scattering properties (Macke et al., 1996). Several attempts have been made to model and simulate light interactions with different ice crystal habits, mixtures of crystal types, aggregates, and aerosols (Baran, 2013), but no single method can easily combine all size ranges and types of particles, making accurate, unified modelling nearly impossible. Scattering analysis is complicated further in small ice crystals and secondary organic aerosol (SOA).

Ice crystals can have different major internal defects (e.g., stacking faults, chemical defects, molecular vacancies, interstitial molecules, ionized states, and orientation defects), surface roughness, and branching with various symmetries. These could be even more influential in small ice measurements. The optical effects of these defects depend strongly on the spatial orientation of the particle. They can lead to systematic biases since particles with a high width to height aspect ratio can have a preferred orientation in chamber measurements (Abdelmonem et al., 2011). However, single particle-by-particle analysis of the backscatter polarization state is useful for particle discrimination as we shall show.

Aerosol particles found in the lower confines of the atmosphere are typically internal or external mixtures of inorganic salts, refractory components such as mineral dusts and clays, and organic species; they also contain varying quantities of water. The hygroscopicity of organic particles is derived from their composition (Cziczo et al., 2004; Jimenez et al., 2009; Duplissy et al., 2011). Pure sulfate and internally mixed organic/sulfate aerosols will have different water uptakes, and consequently different refractive indices. This may lead to mis-sizing by optical instruments if the composition is not taken into account (see Sect. 2.3). In addition to the familiar liquid and crystalline states, atmospheric aerosol may also exist in semi-solid and solid amorphous states (i.e., lacking an ordered, repeating structure) such as soft polymers, gels, or glasses (Mikhailov et al., 2009).
A subset of atmospheric aerosol is the SOA with various viscosities (Renbaum-Wolff et al., 2013). The viscous SOA is expected to appear either in low relative humidity (RH), low temperature environments, or both. A subset of these viscous particles, sometimes referred to as "glassy", (e.g., Koop et al., 2011) or amorphous, are thought to be important components in the atmosphere because of their low volatility, long lifetimes, and their potential impact on several competing processes, which occur during updraft of an air parcel. These include heterogeneous ice nucleation in the deposition mode onto the glassy solid aerosol surface; diffusion of water into the particle, inducing a gradual phase transition towards the liquid state; and immersion freezing during the transition between the states (Berkemeier et al., 2014). Some terpenoids can affect these processes by formation of particles in the glassy state.

In this study we examine alpha-pinene, the most widely encountered terpenoid in nature (Noma and Asakawa, 2010); SOAs derived from alpha-pinene are optically active materials (Wiberg et al., 2004; Cataldo et al., 2010) that induce a change in the polarization state of the scattered radiation. The resulting change to the polarization state of the backscattered light from these aerosol particles can, therefore, be used to probe these effects. Small molecules such as water can soften the structural matrix (as water acts as a plasticizer) of SOA, thus reducing viscosity. As water molecules are removed by drying, the SOA viscosity increases. These highly viscous particles (Renbaum-Wolff et al., 2013) are, therefore, likely to be optically anisotropic (having aspherical shape, branches, roughness, or variations in internal structure) that accentuate the polarization shift of the incident beam in Cloud Aerosol Spectrometer with Polarization (CASPOL). We probe this viscous state in this paper.

\section{The CLOUD chamber and cloudy experiments}

The Cosmics Leaving OUtdoor Droplets (CLOUD) chamber was designed to simulate different atmospheric conditions to reduce the uncertainties for cloud, weather, and general circulation models (Chapter 7 of IPCC 2013; Boucher et al., 2013) and provide new data for the parametrization and modelling of atmospheric processes. The first series of CLOUD experiments at the European Organization for Nuclear Research (CERN) began in 2006 (Duplissy et al., 2010). For several years these experiments were mainly dedicated to aerosol nucleation and growth. Recently, additional experiments focusing on cloud formation have been performed at the CERN chamber. This addition was driven by the importance of ice particles to the Earth's radiation budget and feedback mechanisms. In this paper we focus particularly on results from this cloud particle measurement (Cloudy) series of experiments. The CLOUD chamber utilizes the adiabatic expansion principle to generate super-cooled water and ice clouds, similar to other atmospheric cloud chambers (Möhler et al., 2006; Schnaiter, 2009; Tajiri et al., 2013). In order 
to investigate the microphysics of homogeneous ice nucleation in situ, two sets of Cloudy experiments were conducted during two campaigns at CERN in 2013 and 2014, hereafter referred to as CLOUD 8 and 9, respectively. In this paper we highlight results from some of the mixed-phase cloud measurements as well as new polarization transition measurements for SOA from the photo-oxidation and ozonolysis of alpha-pinene.

\section{Methodology}

\subsection{CLOUD chamber and instrumentation}

The CLOUD chamber was designed in order to achieve excellent temperature stability and very low background aerosol and trace gas concentration levels in order to identify small changes in nucleation rates due to the influence of cosmic rays (Duplissy et al., 2010; Kirkby et al., 2011). An overview of the chamber and more detailed information is presented in the Supplement (Fig. S1). The chamber was equipped with a range of instruments that can measure atmospheric constituents. Aerosol concentrations were measured by a combination of a scanning mobility particle sizer (SMPS; with TSI ${ }^{\mathrm{TM}}$-type, custom-built differential mobility analyser), and an ultra-high sensitivity aerosol spectrometer (UHSAS; Droplet Measurement Technologies) to determine potential cloud condensation nuclei $(\mathrm{CCN})$ concentrations. During CLOUD 8 and 9, instruments for the measurements of cloud droplets and ice particles were added. Cloud particle formation and evolution was measured using several optical spectrometers including a WELAS optical particle counter (WELAS Promo 2000, Palas GmbH) (Benz et al., 2005), a Particle Phase Discriminator (PPD-2K) (Kaye et al., 2008), a 3-View Cloud Particle Imager (3V-CPI, SPEC Inc.) (Lawson et al., 2003), and a Cloud Aerosol Spectrometer with Polarization (CASPOL; Droplet Measurement Technologies) (Baumgardner et al., 2001, 2011; Glen and Brooks, 2013). The latter will be described in more detail in Sect. 2.3.

The procedure for operation of the CLOUD facility as an expansion cloud chamber for ice nucleation studies along with full schematics are described in detail by Guida et al. $(2012,2013)$ and will only briefly be reviewed here. Controlled supersaturated conditions are created in the chamber by allowing air to expand and cool at prescribed rates. The basic operating procedure adopted for all the cloud microphysics experiments was as follows: the chamber was slowly pressurized to $123.3 \mathrm{kPa}$; $\mathrm{CCN}$ were then vaporized and injected through the gas lines; after the $\mathrm{CCN}$ had mixed throughout the chamber volume, a valve was opened allowing the air to expand with the pressure reaching $101.8 \mathrm{kPa}$. The pressure, temperature, and humidity traces for a typical expansion are shown in Fig. 1. Super-saturation occurs due to the pressure reduction and resultant temperature decrease.

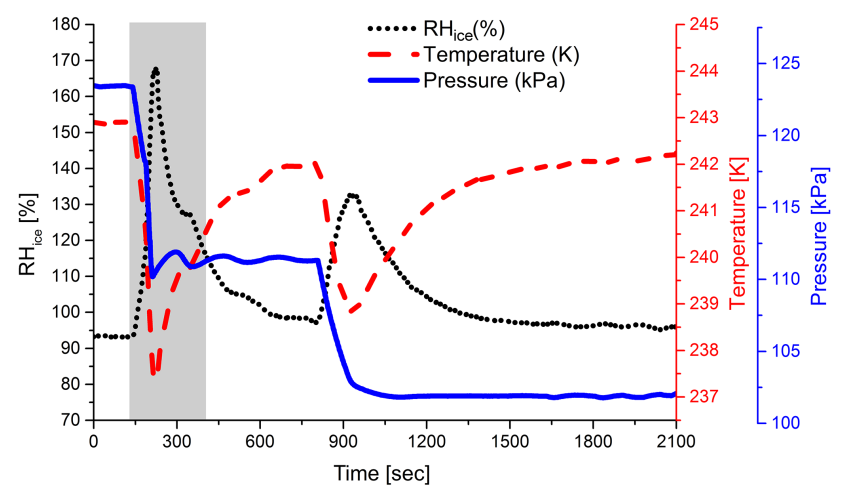

Figure 1. Example of programmable multistep expansion to form a mixed-phase cloud (Run no. 1291.16). Relative humidity with respect to ice $\left(\mathrm{RH}_{\text {ice }}\right)$ calculated from $\mathrm{MBW}$ instrument (MBW373LX) and thermocouples. Second step grows the present ice particles in the cloud period $(25 \mathrm{~min})$. Shaded time period is analysed in Fig. 3.

Before the beginning of the expansion, $\mathrm{RH}$ with respect to liquid water of approximately $92-96 \%$ was achieved. The total humidity in the chamber was measured by dew point mirror instruments (model MBW973 during CLOUD 9 and MBW373LX during CLOUD 8, both from MBW calibration Ltd.) attached to a heated sampling line. Together with the in situ measured gas temperature (six calibrated thermocouples, type $\mathrm{K}$ ) these instruments provide the $\mathrm{RH}$ in the chamber and might overestimate it in the presence of clouds (assuming additional evaporation of cloud droplets in the heated sampling line). During CLOUD 9 a tuneable diode laser (TDL) hygrometer, comparable to the APicT instrument as described by Fahey et al. (2014), was used to measure the water vapour content with $1 \mathrm{~Hz}$ time resolution using a single optical path of $314 \mathrm{~cm}$ once across the middle plane of the CLOUD chamber. Thus, this instrument provides the RH also in the presence of clouds. Subtracting the water vapour content from the total water content results in the condensed (ice or liquid) water content. Sulfuric acid, ammonium sulfate, and oxalic acid particles were used to seed the chamber with $\mathrm{CCN}$ concentrations ranging from 0.5 to several thousand particle $\mathrm{cm}^{-3}$. The CCN number concentrations determined the cloud droplet size, with higher $\mathrm{CCN}$ concentration producing higher concentrations of smaller ice particles in CLOUD.

Although the expansion is, ideally, adiabatic, heat is continuously transferred to the cooled air from the chamber walls, as the temperature control system is maintained at the pre-expansion temperature, resulting in eventual evaporation of the cloud. The cloud lifetime in the CLOUD experiments could be controlled (e.g., by fan speed or by number of steps in the expansion profile) from several minutes to greater than $40 \mathrm{~min}$ when required (e.g., for ice evolution experiments). 
Table 1. Experimental parameters of the expansion runs presented in this paper. Pressure profile $x$ axis is of the order of several minutes.

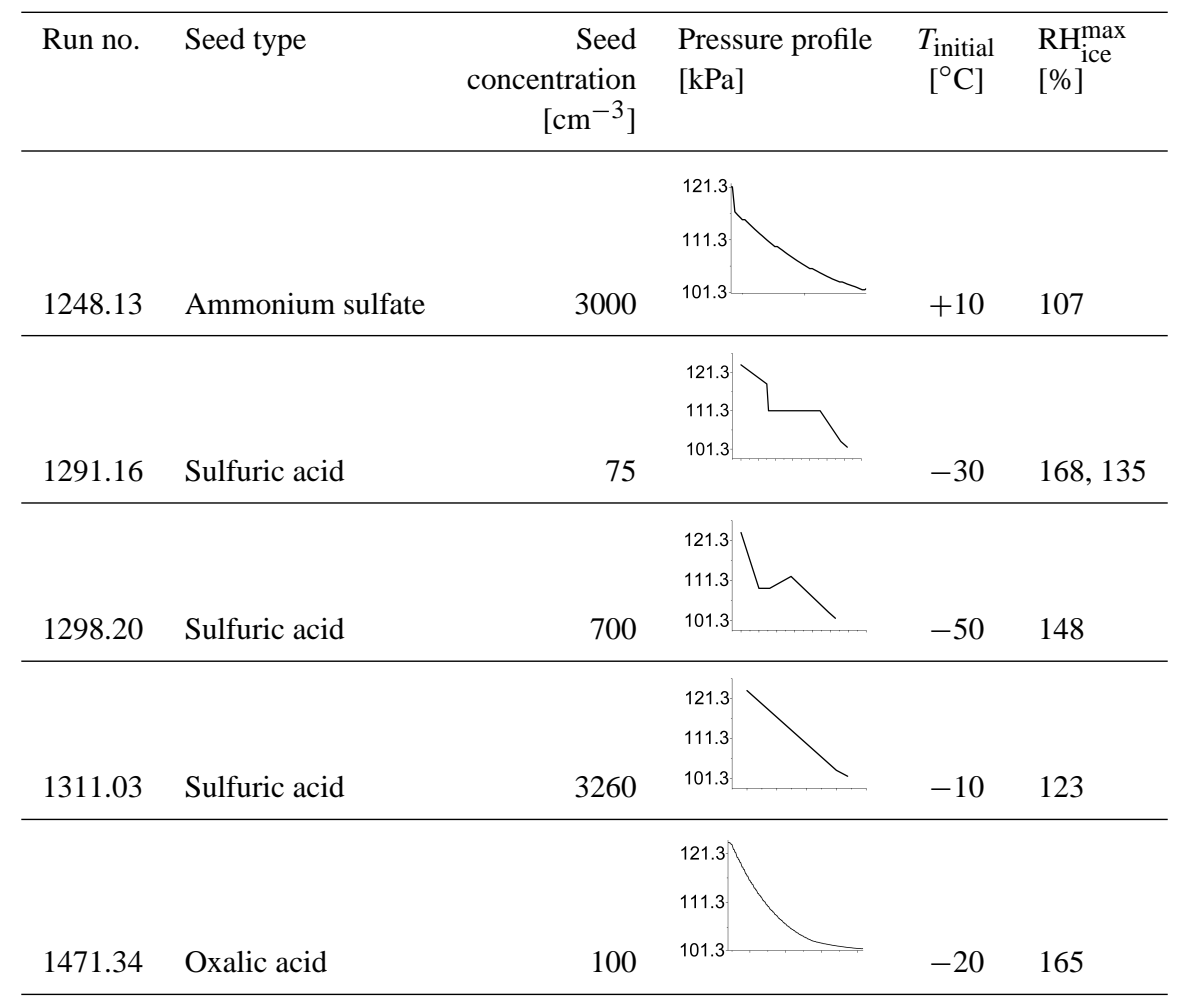

\subsection{Cloud experiment overview}

A series of experiments were conducted to generate liquid clouds (Hoyle et al., 2016), mixed-phase clouds, and pure ice clouds. Controlling stepwise the rate of expansion and the humidity flow into the chamber in the mixed-phase experiments, it was possible to obtain water supersaturation followed by ice supersaturation, allowing $\mathrm{CCN}$ activation to form a cloud for a short period of several minutes. The adiabatic expansion experiments on which this paper focuses are summarized in Table 1, but results based on a much broader database of several hundred CLOUD expansions will also be considered for the discussions.

Several additional experiments were conducted to examine any aerosol polarization state changes arising from possible viscosity changes in response to $\mathrm{RH}$ variations, using CASPOL. A more detailed description of these experiments can be found in the accompanying paper by Järvinen et al. (2015).

\subsection{The CASPOL instrument}

The CASPOL is part of the Cloud Aerosol and Precipitation Spectrometer (CAPS). The first variant of the instrument was introduced in 1999 and was designed for airborne in situ cloud measurements (Baumgardner et al., 2001; Heymsfield, 2007), although it has subsequently been used for cloud chamber measurements (Krämer, 2009). The ver- sion of CASPOL employed here has a linearly polarized laser to provide a collimated incident beam of light at a wavelength of $680 \mathrm{~nm}$.

The first two detectors of the instrument detect the light scattered in the forward direction. The collection of the light cone is subtended by the angles 4 to $12^{\circ}$. The near-forward angles are used for sizing because light is preferentially scattered in the forward direction from particles, whose diameters are larger than the incident wavelength. The first detector in the forward direction is used as a qualifier; it has a rectangular optical mask that restricts scattered light from particles that are outside the centre of focus of the laser beam. Only particles within the optimal view volume are counted and characterized. All data are collected on a single particle basis, thus provide a measure of particle-by-particle variability and single particle optical properties. The particle's water equivalent optical diameter in the range of $0.51-50 \mu \mathrm{m}$ is determined from the forward scattering signal in the second detector using the standard Mie scattering assumptions, i.e., spherical geometry and isotropic refractive index.

The next pair of detectors measures the backscattered light with collection angles of 168 to $176^{\circ}$. The first backscattering detector is used for qualitative particle shape discrimination. The second detector has a polarized filter $\left(90^{\circ}\right.$ to the polarization of the incident light) to measure the change in polarization of scattered light caused by asphericity (Baumgardner et al., 2011; Glen and Brooks, 2013) or birefringence. In 
this configuration, spherical particles produce little response in the perpendicular polarization backscatter detector. Conversely, frozen water droplets and aspherical ice crystals will show much more distinct signals.

In order to eliminate aerosol particle interference in our cloud measurements, only contributions from a subset of larger particles above $3 \mu \mathrm{m}$ were included. This threshold is based on work by Baumgardner et al. (2001) and Lance (2012), who selected a similar size range for cloud particle measurements. In the special case of SOA measurements, a subset of small particles $(<3 \mu \mathrm{m})$ detected in the lower gain stage, was considered.

\section{Calibration}

The CASPOL was calibrated using polystyrene latex spheres (PSL), as described elsewhere, e.g., Droplet Measurement Technologies Manual (2011), Meyer (2011), Rosenberg et al. (2012). Size calibration relates the amplitude of the instrument's response to particle scattering cross sections. Using the Mie-Lorenz curve, the nominal size bin limits can then be defined (Table S2 in the Supplement) in terms of the diameter of water droplets having the same scattering cross section, giving a reasonable estimate of particle size for liquid droplets and small spherical ice particles. Aspherical particles will be mis-sized with respect to spherical particles, subject to their cross section as shown by Borrmann et al. (2000). In our instrument this error would normally be of the order of the size bin width. The uncertainty in the derived polarization ratio is approximately $20 \%$ as described by Baumgardner et al. (2005).

\subsection{Data processing}

\subsubsection{Particle-by-particle analysis}

The polarization ratio measured with the CASPOL instrument and reported in this paper is defined as the ratio of perpendicularly polarized backscatter intensity to total backscatter intensity and provides a measure of the combined phase, composition, and surface features of the particle. This ratio differs from the depolarization ratio that is measured using remote sensing techniques (Groß et al., 2013). The two ratios cannot be directly compared and an additional calibration would be required for this purpose (Meyer, 2011). The ratio of perpendicularly polarized backscatter to forward scatter (Dpol/Fwd) indicates the contribution of particle size to the scattering. Particle-by-particle (PBP) measurements reveal the fraction of aspherical particles population (Fig. 2c) and its evolution. Here we employ cluster analysis on PBP data (Sect. 2.4.2) for phase discrimination and for data quality assurance. This method can also be used to classify highly polarising particles. Adjustments to the forward, backward, and the Dpol channels that have been applied to linearly scale the gain stages are summarized in Table S3.

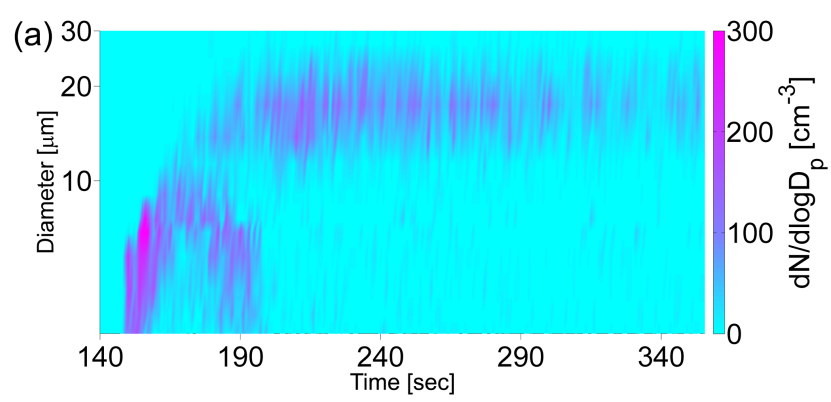

(b) $30 \ldots \ldots+\ldots$
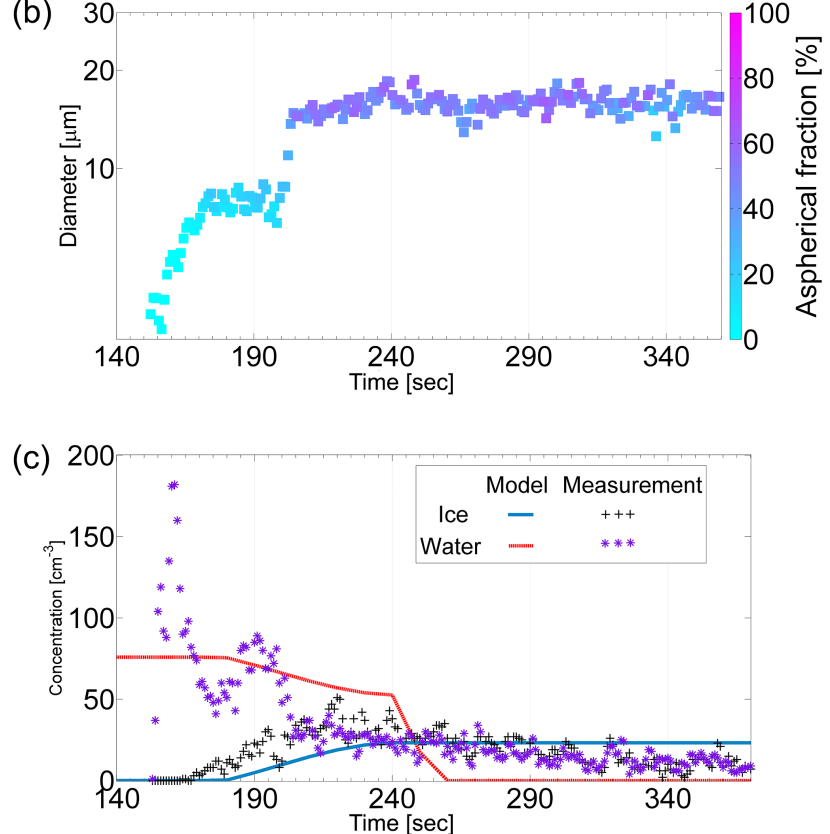

Figure 2. Mixed-phase cloud, phase transition period (Run no. 1291.16). The uncertainty in sizing is of the order of the size bin width (Table S2). The error of the polarization ratio and asphericity is approximately $20 \%$. (a) CASPOL particle-size distribution, (b) CASPOL PBP aspherical fraction, (c) CASPOL measured water and ice concentrations derived from asphericity compared to ACPIM.

\subsubsection{Cluster analysis}

Clustering or grouping of data by the similarity in one variable or a matrix of variables reveals the size of the population with similar properties and the number of the unique groups in the data set, as well as the spread in each group. Clustering analysis is used here to discriminate and assign unique particle properties corresponding to different phases during the experiment (e.g., water, ice), primarily based on variations in the polarization state of the scattered light (Fig. 3). Clustering approaches have been previously used for aerosol property classification, e.g., Omar et al. (2005), Robinson et al. (2013), and Crawford et al. (2015). Here we use the $k$ means cluster function (Seber, 1984; Spath, 1985) from the 

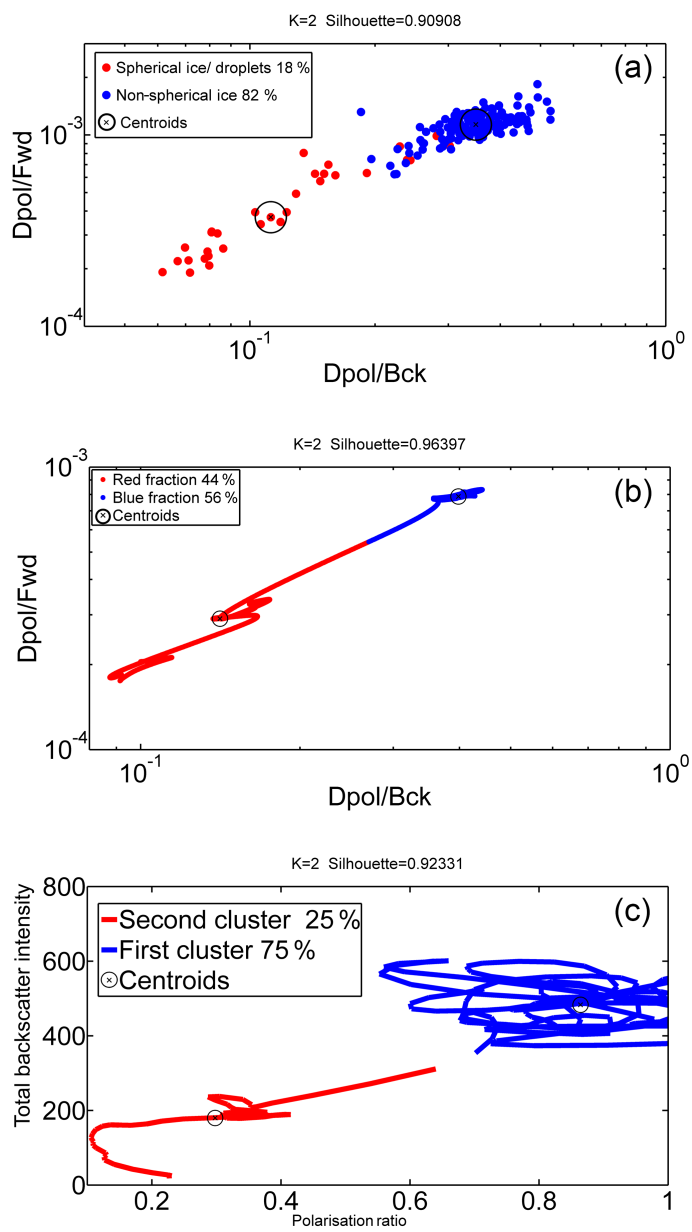

Figure 3. Cluster analysis (Run no. 1291.16). $K$ in the title indicates the number of clusters found with best silhouette value. Each cluster appears with a percentage of particles in it. The centres of clusters are marked by centroids $\odot$. (a) $1 \mathrm{~s}$ averaged data, whole size range, and all concentration, (b) particle-by-particle data clustering for selected size range and concentration thresholds, (c) particle-byparticle data clustering plotted in a space comparable to Glen and Brooks (2013).

MATLAB ${ }^{\circledR}$ statistics toolbox. The algorithm then calculates the minimum total intra-cluster variance:

$\sum_{i=1}^{K} \sum_{x_{j} \in S_{i}} d\left(x_{j}, \mu_{i}\right)$,

where $S_{i}$ is the $i$ th cluster $(i=1, \ldots, K), \mu_{i}$ is the $i$ th centroid of all the points $x_{j}$ in cluster $S_{i}$, and $d$ is the distance function (e.g., squared Euclidean). In this case the function is applied to a matrix of parameter vectors including polarization, size, asphericity, concentration, inter-arrival time, time, etc. This approach should, by itself, be sufficient for discriminating a simple mixture consisting of two discrete and wellseparated phases as may be found in the water-ice particle population. In our aerosol-cloud nucleation experiments, an a priori assumption of cluster number is challenging due to the variability of particles. Initial estimates of cluster numbers (1-7) were tested in sequential iterations. A silhouette index, $s(i)$, was then used to quantitatively assess the quality of clustering, This is a composite index reflecting the compactness and separation of clusters; a larger average silhouette index indicates a better overall quality of the clustering result (Chen et al., 2002). The silhouette value of a point is a measure of the similarity of points within a given cluster compared to those in other clusters; it is defined as

$s(i)=\frac{b(i)-a(i)}{\max (a(i), b(i))}$,

where $a(i)$ is the average distance of the point $i$ to the other points in its own cluster $A . b(i)$ is the minimal average distance of the point $i$ to the points in the other cluster, over all clusters other than $A$ (Eq. 2). For the best possible fit, the silhouette index is, $s(i)=1$. This validation is sufficient for our analysis to indicate the ability of the algorithm to group similar data sets using the prescribed values. Following cluster analysis, asphericity thresholds are selected based on cluster boundaries identified by the colour transition in Fig. 3 and silhouette values greater than 0.9 .

\section{Results}

\subsection{CASPOL water-ice measurements}

As the temperature in the chamber decreases in the multistep expansions, liquid cloud starts to form when the RH exceeds water saturation (Fig. 1). Figure 2a shows the formation of a mixed-phase cloud as a function of time. Droplets formed at sub-zero temperatures are super-cooled and some of them freeze. During the stabilization period, when pressure remains constant, some of the super-cooled droplets evaporate as the walls reheat the chamber. During the second step of the expansion from $t=800 \mathrm{~s}$, the ice grows further. The rapid growth of ice particles depletes the available water vapour, causing the remaining liquid droplets to evaporate by the Bergeron-Findeisen mechanism. The aspherical fraction (Fig. 2b), and the concentrations of water and ice (Fig. 2c) were calculated from the PBP cluster analysis for each of these conditions during the run. Images of some typical ice particles (diameter $<150 \mu \mathrm{m}$ ) from the Cloudy experiments were captured by the $3 \mathrm{~V}-\mathrm{CPI}$. These diverse experiments produced ice habits that included needles, hexagonal plates, columns, bullets, and dendrites; ice aggregates and spheroids were also detected (Fig. 4). These habits scatter the light differently. However, CASPOL data were in good agreement with ice measurements by the PPD, small water droplets measured with WELAS (Figs. S4 and S5). 


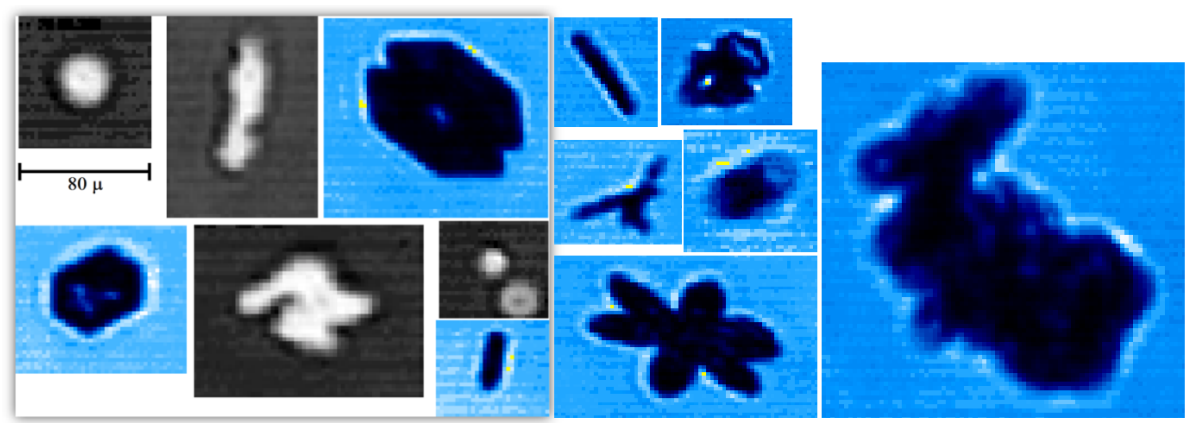

Figure 4. Images of ice particles in CLOUD captured by $3 \mathrm{~V}-\mathrm{CPI}$ with $2 \mu \mathrm{m}$ resolution. Most of the particles are smaller than $100 \mu \mathrm{m}$ (scale on the left).

Table 2. SOA growth experimental conditions of the presented runs.

\begin{tabular}{cccc}
\hline Run & $\begin{array}{c}T \\
{\left[{ }^{\circ} \mathrm{C}\right]}\end{array}$ & $\begin{array}{c}\text { Initial } \\
\mathrm{RH} \\
{[\%]}\end{array}$ & $\begin{array}{c}\text { Max. concentration } \\
{\left[\times 1000 \mathrm{~cm}^{-3}\right]} \\
(\text { diameter }>10 \mathrm{~nm})\end{array}$ \\
\hline 1313 & +10 & 12 & 30 \\
1513 & -20 & 60 & 45 \\
1514 & -20 & 4 & 40 \\
1515 & -30 & 2 & 30 \\
1516 & -38 & 5 & 45 \\
\hline
\end{tabular}

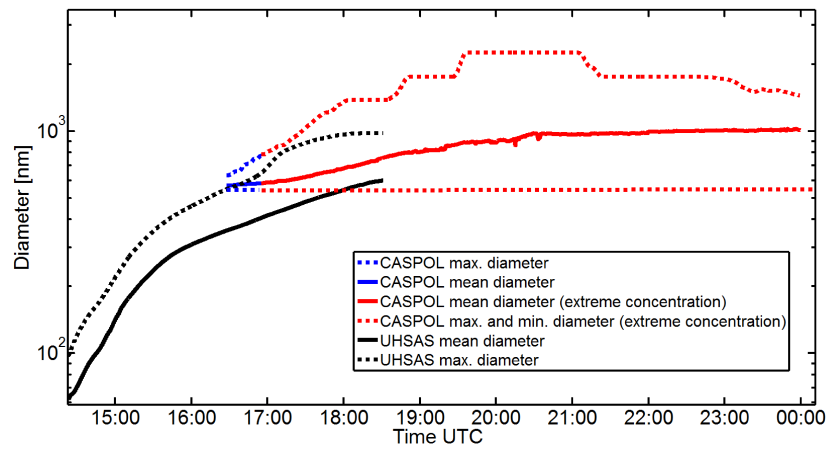

\subsection{ACPIM modelling}

Validation of ice formation was done by modelling. A modelling tool used in this analysis is the aerosol-cloudprecipitation interaction model (ACPIM), which has been developed at the University of Manchester in collaboration with the Karlsruhe Institute of Technology (Connolly et al., 2009). Temperature time series were plotted using the initial experimental conditions (e.g., chamber temperature, pressure, $\mathrm{RH}$, and $\mathrm{CCN}$ concentration) in the model. Subsequent fitting of the simulated temperature drop to chamber data enabled us to find the rate at which the chamber reheats after expansion $\left(0.007 \mathrm{~s}^{-1}\right)$ for the runs specified in Table 1 . This heat exchange coefficient is in a good agreement with the results found by Dias et al. (2016). It quantifies how effectively heat is transferred from the chamber walls and mixed throughout the gas in this chamber.

ACPIM was able to replicate the observed particle phase transitions in the mixed-phase runs, thereby validating the phase concentration plot (Fig. 2c). Phase concentration deviations at the beginning of the expansion were probably caused by inhomogeneity in the chamber due to incomplete mixing, or by variations in the expansion rate. Ambiguous polarization states of water, e.g., in super-cooled or frozen droplets, might be resolved by comparing ACPIM to CASPOL data and examining the mismatch. This simulation of the experiment makes it possible to predict phase concen-

Figure 5. SOA growth over a $10 \mathrm{~h}$ period, $1 \mathrm{~Hz}$ sampling rate (Run no. 1516). CASPOL and UHSAS overlapped size measurements. Black lines - particles measured with UHSAS, instrument's cut-off is at $1000 \mathrm{~nm}$. Blue lines - particles measured with CASPOL. Red lines indicate that CASPOL has passed the saturation threshold and the measurements may be subject to coincidence errors.

trations and sizes, supporting the planning of future experiments and validation of the theories behind the model.

\subsection{Viscous SOA measurements}

The validated discrimination method used in water-ice phase transition analysis was subsequently applied to investigate SOA phase transition. The viscous SOA growth experiments reported here were achieved using a controlled, constant flow of precursor gases and ozone into the chamber at constant, near-ambient pressure, dry conditions, and constant temperatures, as shown in Table 2 (for details see Järvinen et al., 2015). We observe a growth in particle diameter from tens of nanometres to more than $1 \mu \mathrm{m}$ size particles. During these growth periods (Fig. 5), an increase in the CASPOL backscatter polarization ratio was observed. A large part of the experiment produced extreme particle concentrations above the recommended CASPOL concentration limit of $1300 \mathrm{~cm}^{-3}$, where significant coincidence errors would be likely to occur (D. Baumgardner, personal commu- 

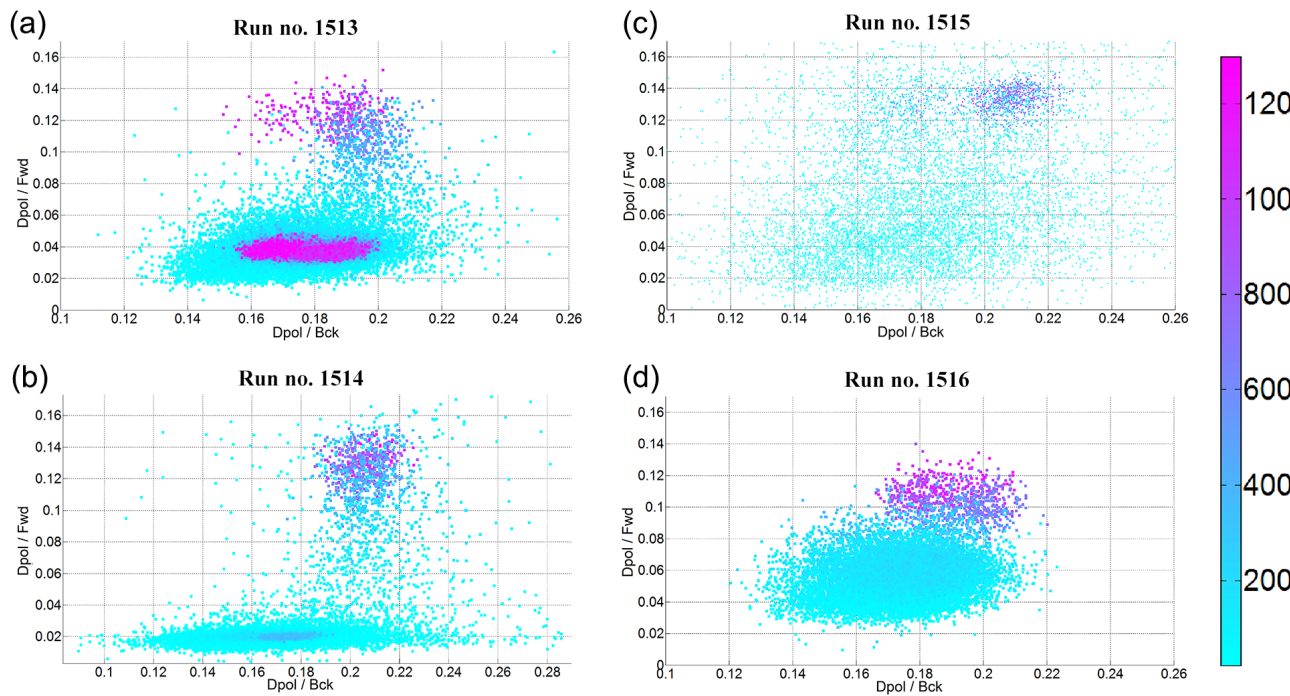

1200

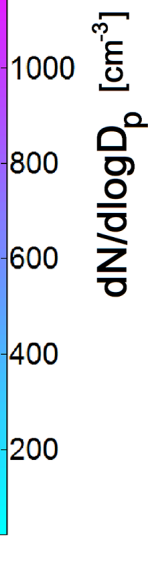

Figure 6. Polarization scatter plots of SOA growth and liquefaction measured by CASPOL in four experiments. Ratio of perpendicularly polarized backscatter to forward scatter intensity (Dpol/Fwd) vs. ratio of perpendicularly polarized backscatter intensity to total backscatter intensity (Dpol/Bck), $1 \mathrm{~s}$ averaged run periods where the concentration was below $1300 \mathrm{~cm}^{-3}$, colour is concentration $\mathrm{d} N / \mathrm{dlog} D_{\mathrm{p}}\left[\mathrm{cm}{ }^{-3}\right.$ ], (a) run no. 1513, (b) run no. 1514, (c) run no. 1515, (d) run no. 1516.

nication, 2015). Therefore, we limit our discussion to conditions in which growth to sizes larger than $0.56 \mu \mathrm{m}$ in diameter, and concentrations below $1300 \mathrm{~cm}^{-3}$ occur (for details see Sect. 4). After the growth, RH was increased up to $80 \%$ in each experiment in order to observe the phase transitions using optical depolarization measurements as reported by Järvinen et al. (2015). Several repetitions of these growth experiments followed by humidification and phase transition were conducted. The subsequent glass transition formed liquid particles at the end of each experiment. A lower particle polarization (more optically spherical) state was detected by the CASPOL at this stage. As a consequence, we observed the presence of two distinct polarization clusters during the growth where highly viscous SOA is expected and after the phase transition where we expect to see liquid particles. The two clusters are overlaid for several experiments as shown in Fig. 6.

While cooling the chamber and reducing the RH (Run no. 1515.16) (Fig. 7), the larger optically semi-spherical particles started to dry. Oxidized alpha-pinene SOA compounds generally have added functional groups (oxygen containing substituents), high polarity, and, thus, lower vapour pressure (Pandis et al., 1992) than water. As a result of this drying process and the dynamics of partitioning, CASPOL measures an increase in polarization. The detailed dynamics of partitioning in SOA from alpha-pinene ozonolysis is described in Donahue et al. (2014).

The increase in the measured polarization could be explained as a transition to an amorphous aerosol phase with high viscosity at $\mathrm{RH} \sim 10 \%, T=-30$ to $-38^{\circ} \mathrm{C}$, $P=102 \mathrm{kPa}$ as suggested by the hysteresis plot of Koop et

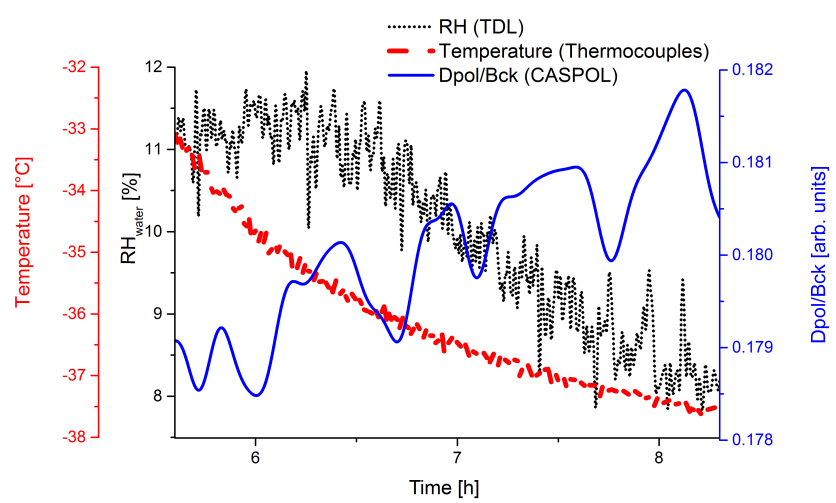

Figure 7. CASPOL filtered polarization ratio (blue line) increases as RH (black dotted line) decreases during the cooling period after a SOA experiment (Run no. 1515.16).

al. (2011). Our results cannot, however, be unambiguously ascribed to the viscosity transition based solely on the measurements here. We simply note the ability of the CASPOL to identify significant polarization shifts in the aerosol scattering properties that are likely associated with changes in their physico-chemical properties.

Additional support for this hypothesis comes from SMPS measurements. No particles were detected in the SMPS size range in the transition period; the upper cut-off of the measurement was about $400 \mathrm{~nm}$. A small decay of the averaged diameter is observed in CASPOL (Fig. 8). These data indicate a wet to dry transformation of large particles. This reversed transition of the viscosity is then followed by partitioning or dissociation within these particles, and a decrease 


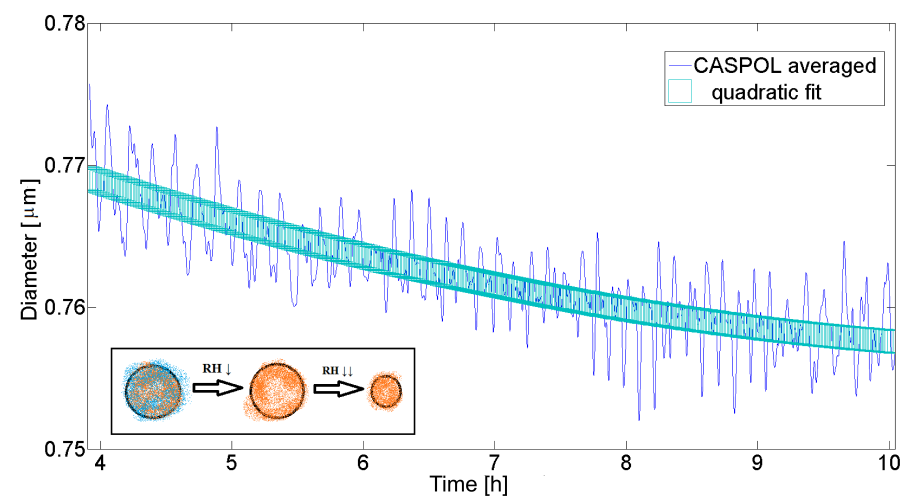

Figure 8. Large dry particles decrease in size. Inset: illustration of the hypothesized transition sequence from CASPOL and SMPS measurements (liquid to viscous and dried further).

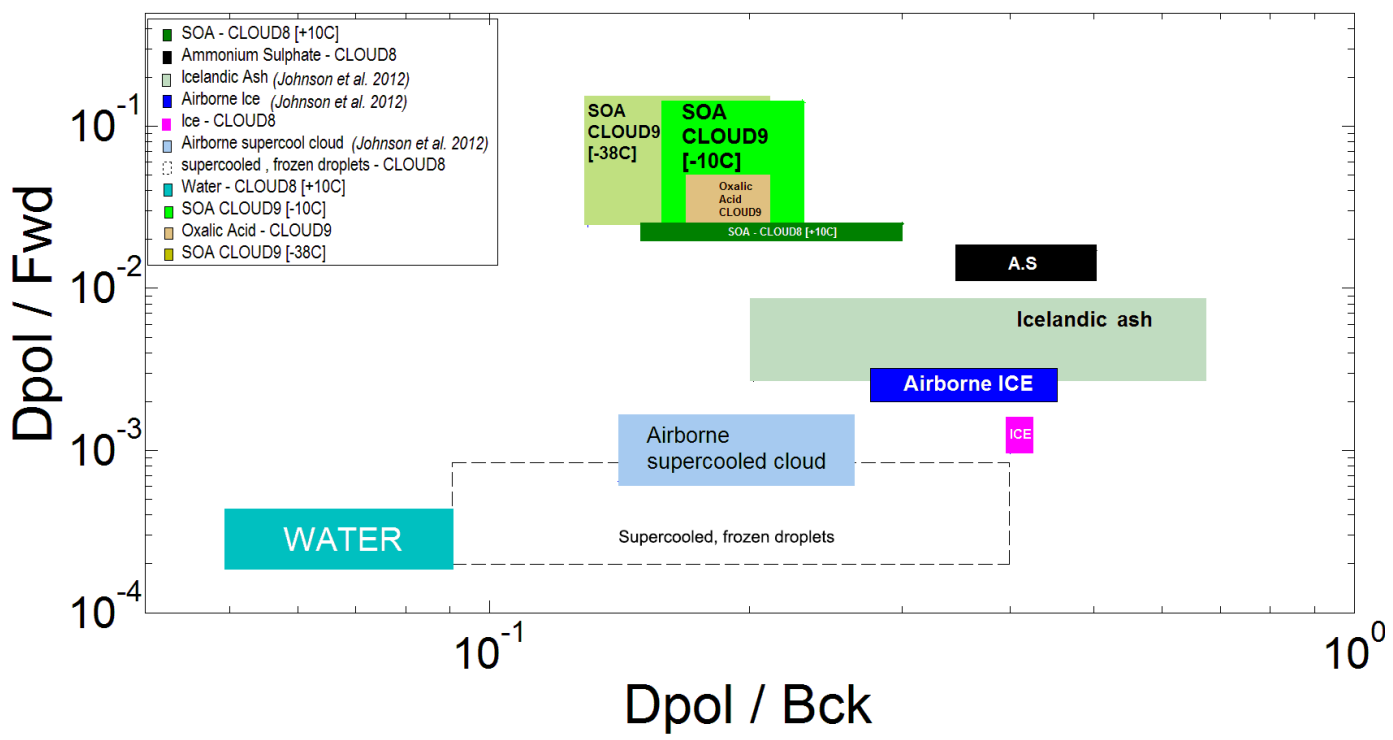

Figure 9. Atmospheric particle classification map for CLOUD data. The dimensions of the coloured rectangular boxes represent the space of measurements error and data points' distribution. Additional CASPOL data points from aircraft measurements are presented for comparison (Johnson et al., 2012).

in their concentration and sizes due to constantly decreasing RH.

\subsection{Particle classification maps}

In order to map the whole range of atmospheric processes under future emissions scenarios, it will be necessary to identify the particles. A new strategy to categorize dust groupings was developed by Glen and Brooks $(2013,2014)$ whereby optical scattering signatures from CASPOL measurements were used to develop a set of threshold rules based on polarization ratios. These rules can be used to classify types of dust sampled in the laboratory and during field campaigns. A plot of the total backscatter intensity as a function of the polarization ratio for various types of dust clearly shows the difference in their signatures. Similar techniques for clas- sifying aerosols are already in use by the light detection and ranging (lidar) community (Burton et al., 2012; Petzold et al., 2010). To explore the feasibility of using the signature method in CLOUD, we have collated polarization ratio ranges of many particles measured in the CLOUD 8 and 9 campaigns. Here we present the polarization map (Fig. 9) combining the CLOUD campaign measurements with those obtained from aircraft flights over the North Sea (Johnson et al., 2012) using the same CASPOL instrument. This map makes it possible to predict the coordinates of other potential organic compounds in the upper area. Salts, ash, and ice are in the upper-range of the Dpol/Bck ratio; spherical liquids are at the bottom. Further size dependant separation might be possible on the $y$ axis. More experimental data are needed to fill the space for other particles, temperatures, and RH. 
Classification of small ice and water by size characteristics has limited accuracy (Heymsfield et al., 2006). As explained earlier, CASPOL can differentiate between the asphericities of the particles. The ice presented on this map is aspherical. Slight changes in the polarization state of droplets can also be observed as the droplets cool and a crystalline pattern emerges. This discrimination technique could be used in chamber measurements with mixtures of $\mathrm{CCN}$ and ice nuclei (IN) and with some limitations could be applied in explicit atmospheric measurements albeit with higher uncertainty due to potentially significant overlap in polarization responses, particularly in a real environment with high diversity of particles.

\section{Discussion}

The results presented in this paper (Figs. 2, 5, S4, and S5) illustrate the ability of the CASPOL instrument to provide reliable particle-size distribution in expansion chamber campaigns, and to classify atmospheric particles of different phases, viscosities, shapes, and sizes. The polarization ratio was combined with the PBP clustering technique to highlight the time-resolved aspherical fraction evolution.

Despite the known limitations and uncertainties in these measurements, e.g., particle sedimentation (Chapter 6 in Kulkarni et al., 2011), electronic "ringing", and leakage currents (Kramer, 2002), these did not affect the filtered results (Fig. 3b and c) shown here. Another uncertainty is contributed by the extremely high aerosol concentrations $\sim 40000 \mathrm{~cm}^{-3}$ (with unresolvable inter-arrival times between successive particle). These concentrations may not be atmospherically relevant; their role here was solely to grow the larger SOA particles $(>500 \mathrm{~nm})$. This was required to allow the optical detection of particles during growth and liquefaction.

In addition to concentration issues, a derivation of equivalent diameters from dry viscous aerosol particles may be challenging since it has been argued that spherical aerosols can be considered as purely a "figment of the imagination" (Baran, 2013). However, particle sizes measured by CASPOL and UHSAS during SOA growth corresponded well. The predicted SOA behaviour (Koop et al., 2011) and the measured slow increase of polarization may suggest a change in the viscosity of these particles. The polarization transitions observed were both clear and repeatable, which increases confidence in our ability to identify the hypothesized transitions and to place these observations on the general polarization map for classification in a comparative particle analysis.

The general classification map presented here demonstrates a good agreement between chamber and airborne measurements (Fig. 9). Although super-cooled droplets, ice, and other particle polarization footprints seem to be quite distinct, it is clear that further spatial growth and branching of ice could lead to a significant increase in polarization and possibly significant overlapping of different species. One of the aims of future studies would be to test aggregation and branching impacts on CASPOL signals. Slightly different ratios of the airborne super-cooled droplets and ice might be the result of aerosol ageing. Processes such as aerosol ageing will influence subsequent phase separation processes within the droplet but are difficult to reproduce in a chamber.

In the real atmosphere, the particles are more complex; contain additional polarising constituents and have more branching. Froyd et al. (2010) reported the coexistence of mixtures of partially or fully neutralized sulfate with organic material, nucleated ice crystals, dry ammonium sulfate, and glassy particles in the Tropical Troposphere Layer (TTL). Ice residuals were also similar in size to unfrozen aerosol. Lawson et al. (2008) suggested a thorough investigation of nucleation and growth mechanisms of ice particles in TTL at low temperatures is needed, particularly in the presence of sulfates mixed with organics and very high relative humidity. This might be difficult due to increasing anthropogenic $\mathrm{SO}_{2}$ emissions, which may increase the formation of sulfuric acid aerosols and thus small ice crystals in the TTL (Notholt et al., 2005). The increase in small ice concentration in the presence of aerosols may complicate ice content measurements even further. The classification map presented here represents one approach to facilitate future CASPOLPBP data analysis of the TTL and deep convective outflow regions. It could also be useful for particles like ammonium sulfate that often reach high altitudes through the seasonal biomass burning processes and initiate ice nucleation. Using a method such as the classification map presented here to discriminate between different kinds of atmospheric particles (e.g., ice crystals, ammonium sulfate, volcanic ash, SOA) will allow for better insight for atmospheric transport and chemical processes.

\section{Conclusions}

The CLOUD 8-9 campaigns at the CERN facility introduced a new capability of this facility for cloud particle measurements (Cloudy). In this paper the first CASPOL Cloudy measurements of mixed phase and ice clouds are presented. We discuss the advantages of particle-by-particle analysis of the polarization. Single-particle polarization was used here to discriminate water, ice, SOA, and other atmospheric particles. The capability to detect viscous oxidized alpha-pinene with the CASPOL is reported for the first time.

We present observation of reversed transition from liquid to viscous based on CASPOL, SMPS measurements, and SOA modelling. In our experiments, the SOA viscous to liquid transition is shown to be a reversible process. This result contributes to our understanding of viscous SOA appearance in the atmosphere, ageing, and potentially to the solar radiation budget calculations. 
Classification using the clustering technique produced a classification map that can contribute to future chamber and, possibly, atmospheric measurements of small particles with CASPOL in a heterogeneous environment. Small ice particles formed during different stages of the cloud still pose a great challenge for the optical instruments. Future efforts will focus on classification of additional cloud particles using CASPOL.

\section{The Supplement related to this article is available online at doi:10.5194/acp-16-3651-2016-supplement.}

Acknowledgements. We would like to thank CERN for supporting CLOUD with important technical and financial resources, and for providing a particle beam from the CERN Proton Synchrotron. We express great appreciation for the CLOUD collaboration and the volunteers for the night shifts. We would also like to thank Darrel Baumgardner for CASPOL data filtering advice and review of the manuscript. T. B. Kristensen gratefully acknowledges funding from the German Federal Ministry of Education and Research (BMBF) through the CLOUD12 project. This research has received funding from the EC Seventh Framework Programme (Marie Curie Initial Training Network "CLOUD-TRAIN" no. 316662) and Swiss National Science Foundation (SNSF) grant no. 200021_140 663. The CAPS instrument used in this work was supplied by the National Centre for Atmospheric Science. The UHSAS was funded by NERC grant NE/B504873/1.

Edited by: V.-M. Kerminen

\section{References}

Abdelmonem, A., Schnaiter, M., Amsler, P., Hesse, E., Meyer, J., and Leisner, T.: First correlated measurements of the shape and light scattering properties of cloud particles using the new Particle Habit Imaging and Polar Scattering (PHIPS) probe, Atmos. Meas. Tech., 4, 2125-2142, doi:10.5194/amt-4-2125-2011, 2011.

Baran, A.: Light scattering by irregular particles in the Earth's atmosphere, in: Light Scattering Reviews 8, edited by: Kokhanovsky, A. A., Springer Praxis Books, Berlin, Heidelberg, Germany, 368, 2013.

Baumgardner, D., Jonsson, H., Dawson, W., O'Connor, D., and Newton, R.: The cloud, aerosol and precipitation spectrometer: a new instrument for cloud investigations, Atmos. Res., 59, 251264, doi:10.1016/S0169-8095(01)00119-3, 2001.

Baumgardner, D., Chepfer, H., Raga, G. B., and Kok, G. L.: The shapes of very small cirrus particles derived from in situ measurements, Geophys. Res. Lett., 32, L01806, doi:10.1029/2004GL021300, 2005.

Baumgardner, D., Brenguier, J. L., Bucholtz, A., Coe, H., DeMott, P., Garrett, T. J., Gayet, J. F., Hermann, M., Heymsfield, A., Korolev, A., Krämer, M., Petzold, A., Strapp, W., Pilewskie, P., Taylor, J., Twohy, C., Wendisch, M., Bachalo, W., and Chuang, P.: Airborne instruments to measure atmospheric aerosol particles, clouds and radiation: a cook's tour of mature and emerging technology, Atmos. Res., 102, 10-29, doi:10.1016/j.atmosres.2011.06.021, 2011.

Benz, S., Megahed, K., Möhler, O., Saathoff, H., Wagner, R., and Schurath, U.: $T$-dependent rate measurements of homogeneous ice nucleation in cloud droplets using a large atmospheric simulation chamber, J. Photoch. Photobio. A, 176, 208-217, doi:10.1016/j.jphotochem.2005.08.026, 2005.

Berkemeier, T., Shiraiwa, M., Pöschl, U., and Koop, T.: Competition between water uptake and ice nucleation by glassy organic aerosol particles, Atmos. Chem. Phys., 14, 12513-12531, doi:10.5194/acp-14-12513-2014, 2014.

Borrmann, S., Luo, B., and Mishchenko, M.: Application of the T-matrix method to the measurement of aspherical (ellipsoidal) particles with forward scattering optical particle counters, J. Aerosol Sci., 31, 789-799, doi:10.1016/S0021-8502(99)005637, 2000.

Boucher, O., Randall, D., Artaxo, P., Bretherton, C., Feingold, G., Forster, P., Kerminen, V.-M., Kondo, Y., Liao, H., Lohmann, U., Rasch, P., Satheesh, S. K., Sherwood, S., Stevens, B., and Zhang, X. Y.: Clouds and aerosols, in: Climate Change 2013: The Physical Science Basis, Contribution of Working Group I to the Fifth Assessment Report of the Intergovernmental Panel on Climate Change, edited by: Stocker, T. F., Qin, D., Plattner, G.-K., Tignor, M., Allen, S. K.,Boschung, J., Nauels, A., Xia, Y., Bex, V., and Midgley, P. M., Cambridge University Press, Cambridge, UK, New York, USA, 571-657, 2013.

Burton, S. P., Ferrare, R. A., Hostetler, C. A., Hair, J. W., Rogers, R. R., Obland, M. D., Butler, C. F., Cook, A. L., Harper, D. B., and Froyd, K. D.: Aerosol classification using airborne high spectral resolution lidar measurements - methodology and examples, Atmos. Meas. Tech., 5, 73-98, doi:10.5194/amt-5-73-2012, 2012.

Cataldo, F., Ursini, O., Lilla, E., and Angelini, G.: Ozonolysis of $\alpha$ pinene, $\beta$-, $d$ - and $l$-turpentine oil studied by chirooptical methods; some implications on the atmospheric chemistry of biogenic volatile organic compounds, Ozone-Sci. Eng., 32, 274 285, doi:10.1080/01919512.2010.493550, 2010.

Chen, G., Jaradat, S. A., Banerjee, N., Tanaka, T. S., Ko, M. S. H., and Zhang, M. Q.: Evaluation and comparison of clustering algorithms in analyzing ES cell gene expression data, Stat. Sinica, 12, 241-262, 2002.

Connolly, P. J., Möhler, O., Field, P., Saathoff, H., Burgess, R., Choularton, T., and Gallagher, M.: Studies of heterogeneous freezing by three different desert dust samples, Atmos. Chem. Phys., 9, 2805-2824, doi:10.5194/acp-9-2805-2009, 2009.

Crawford, I., Ruske, S., Topping, D. O., and Gallagher, M. W.: Evaluation of hierarchical agglomerative cluster analysis methods for discrimination of primary biological aerosol, Atmos. Meas. Tech., 8, 4979-4991, doi:10.5194/amt-8-4979-2015, 2015.

Cziczo, D. J., DeMott, P. J., Brooks, S. D., Prenni, A. J., Thomson, D. S., Baumgardner, D., Wilson, J. C., Kreidenweis, S. M., and Murphy, D. M.: Observations of organic species and atmospheric ice formation, Geophys. Res. Lett., 31, L12116, doi:10.1029/2004GL019822, 2004.

Dias, A., Ehrhart, S., Vogel, A., Williamson, C., Simões, J., Kirkby, J., Mathot, S., and Onnela, A.: Analysis of temperature homogeneity of the CLOUD chamber at CERN, in preparation, 2016.

Donahue, N., Robinson, A., Trump, E., Riipinen, I., and Kroll, J.: Volatility and aging of atmospheric organic aerosol, in: Atmospheric and Aerosol Chemistry, edited by: McNeill, V. F. and 
Ariya, P. A., Topics in Current Chemistry, Springer, Berlin, Heidelberg, Germany, 97-143, 2014.

Droplet Measurement Technologies Manual: CAPS operator manual, DOC-0066 Revision F, DMT, Boulder, Colorado, USA, 2011.

Duplissy, J., Enghoff, M. B., Aplin, K. L., Arnold, F., Aufmhoff, H., Avngaard, M., Baltensperger, U., Bondo, T., Bingham, R., Carslaw, K., Curtius, J., David, A., Fastrup, B., Gagné, S., Hahn, F., Harrison, R. G., Kellett, B., Kirkby, J., Kulmala, M., Laakso, L., Laaksonen, A., Lillestol, E., Lockwood, M., Mäkelä, J., Makhmutov, V., Marsh, N. D., Nieminen, T., Onnela, A., Pedersen, E., Pedersen, J. O. P., Polny, J., Reichl, U., Seinfeld, J. H., Sipilä, M., Stozhkov, Y., Stratmann, F., Svensmark, H., Svensmark, J., Veenhof, R., Verheggen, B., Viisanen, Y., Wagner, P. E., Wehrle, G., Weingartner, E., Wex, H., Wilhelmsson, M., and Winkler, P. M.: Results from the CERN pilot CLOUD experiment, Atmos. Chem. Phys., 10, 1635-1647, doi:10.5194/acp-101635-2010, 2010.

Duplissy, J., DeCarlo, P. F., Dommen, J., Alfarra, M. R., Metzger, A., Barmpadimos, I., Prevot, A. S. H., Weingartner, E., Tritscher, T., Gysel, M., Aiken, A. C., Jimenez, J. L., Canagaratna, M. R., Worsnop, D. R., Collins, D. R., Tomlinson, J., and Baltensperger, U.: Relating hygroscopicity and composition of organic aerosol particulate matter, Atmos. Chem. Phys., 11, 11551165, doi:10.5194/acp-11-1155-2011, 2011.

Fahey, D. W., Gao, R.-S., Möhler, O., Saathoff, H., Schiller, C., Ebert, V., Krämer, M., Peter, T., Amarouche, N., Avallone, L. M., Bauer, R., Bozóki, Z., Christensen, L. E., Davis, S. M., Durry, G., Dyroff, C., Herman, R. L., Hunsmann, S., Khaykin, S. M., Mackrodt, P., Meyer, J., Smith, J. B., Spelten, N., Troy, R. F., Vömel, H., Wagner, S., and Wienhold, F. G.: The AquaVIT-1 intercomparison of atmospheric water vapor measurement techniques, Atmos. Meas. Tech., 7, 3177-3213, doi:10.5194/amt-7-3177-2014, 2014.

Froyd, K. D., Murphy, D. M., Lawson, P., Baumgardner, D., and Herman, R. L.: Aerosols that form subvisible cirrus at the tropical tropopause, Atmos. Chem. Phys., 10, 209-218, doi:10.5194/acp10-209-2010, 2010.

Glen, A. and Brooks, S. D.: A new method for measuring optical scattering properties of atmospherically relevant dusts using the Cloud and Aerosol Spectrometer with Polarization (CASPOL), Atmos. Chem. Phys., 13, 1345-1356, doi:10.5194/acp-13-13452013, 2013.

Glen, A. and Brooks, S. D.: Single particle measurements of the optical properties of small ice crystals and heterogeneous ice nuclei, Aerosol Sci. Tech., 48, 1123-1132, doi:10.1080/02786826.2014.963023, 2014.

Groß, S., Esselborn, M., Weinzierl, B., Wirth, M., Fix, A., and Petzold, A.: Aerosol classification by airborne high spectral resolution lidar observations, Atmos. Chem. Phys., 13, 2487-2505, doi:10.5194/acp-13-2487-2013, 2013.

Guida, R., Carrie, P., De Menezes, L., Duplissy, J., Fayet, F., Kirkby, J., Mathot, S., Minginette, P., Onnela, A., Rochez, J., Thomas, G., Wasem, A., and Wilhelmsson, M.: An ultra-pure gas system for the CLOUD experiment at CERN, in: 2012 IEEE Nuclear Science Symposium and Medical Imaging Conference (NSS/MIC), 27 October-3 November 2012, Anaheim, CA, 1199-1203, 2012.

Guida, R., Carrie, P., De Menezes, L., Duplissy, J., Fayet, F., Haider, S., Kirkby, J., Mathot, S., Minginette, P., Onnela, A., Rochez,
J., Thomas, G., Wasem, A., and Wilhelmsson, M.: Development of the gas system for the CLOUD experiment at CERN, in: 2013 IEEE Nuclear Science Symposium and Medical Imaging Conference (NSS/MIC), 27 October-2 November 2013, Seoul, $1-5,2013$.

Heymsfield, A. J.: On measurements of small ice particles in clouds, Geophys. Res. Lett., 34, L23812, doi:10.1029/2007GL030951, 2007.

Heymsfield, A. J., Schmitt, C., Bansemer, A., van Zadelhoff, G.-J., McGill, M. J., Twohy, C., and Baumgardner, D.: Effective Radius of Ice Cloud Particle Populations Derived from Aircraft Probes, J. Atmos. Ocean. Tech., 23, 361-380, doi:10.1175/JTECH1857.1, 2006.

Hoyle, C. R., Fuchs, C., Järvinen, E., Saathoff, H., Dias, A., El Haddad, I., Gysel, M., Coburn, S. C., Tröstl, J., Bernhammer, A.-K., Bianchi, F., Breitenlechner, M., Corbin, J. C., Craven, J., Donahue, N. M., Duplissy, J., Ehrhart, S., Frege, C., Gordon, H., Höppel, N., Heinritzi, M., Kristensen, T. B., Molteni, U., Nichman, L., Pinterich, T., Prévôt, A. S. H., Simon, M., Slowik, J. G., Steiner, G., Tomé, A., Vogel, A. L., Volkamer, R., Wagner, A. C., Wagner, R., Wexler, A. S., Williamson, C., Winkler, P. M., Yan, C., Amorim, A., Dommen, J., Curtius, J., Gallagher, M. W., Flagan, R. C., Hansel, A., Kirkby, J., Kulmala, M., Möhler, O., Stratmann, F., Worsnop, D. R., and Baltensperger, U.: Aqueous phase oxidation of sulphur dioxide by ozone in cloud droplets, Atmos. Chem. Phys., 16, 1693-1712, doi:10.5194/acp-16-16932016, 2016.

Järvinen, E., Ignatius, K., Nichman, L., Kristensen, T. B., Fuchs, C., Höppel, N., Corbin, J. C., Craven, J., Duplissy, J., Ehrhart, S., El Haddad, I., Frege, C., Gates, S. J., Gordon, H., Hoyle, C. R., Jokinen, T., Kallinger, P., Kirkby, J., Kiselev, A., Naumann, K.-H., Petäjä, T., Pinterich, T., Prevot, A., Saathoff, H., Schiebel, T., Sengupta, K., Simon, M., Tröstl, J., Virtanen, A., Vochezer, P., Vogt, S.,Wagner, A. C.,Wagner, R., Williamson, C., Winkler, P. M., Yan, C., Baltensperger, U., Donahue, N. M., Flagan, R. C., Gallagher, M., Hansel, A., Kulmala, M., Stratmann, F., Worsnop, D. R., Möhler, O., Leisner, T., and Schnaiter, M.: Observation of viscosity transition in $\alpha$-pinene secondary organic aerosol, Atmos. Chem. Phys. Discuss., 15, 28575-28617, doi:10.5194/acpd-15-28575-2015, 2015.

Jimenez, J. L., Canagaratna, M. R., Donahue, N. M., Prevot, A. S. H., Zhang, Q., Kroll, J. H., DeCarlo, P. F., Allan, J. D., Coe, H., Ng, N. L., Aiken, A. C., Docherty, K. S., Ulbrich, I. M., Grieshop, A. P., Robinson, A. L., Duplissy, J., Smith, J. D., Wilson, K. R., Lanz, V. A., Hueglin, C., Sun, Y. L., Tian, J., Laaksonen, A., Raatikainen, T., Rautiainen, J., Vaattovaara, P., Ehn, M., Kulmala, M., Tomlinson, J. M., Collins, D. R., Cubison, M. J., E., Dunlea, J., Huffman, J. A., Onasch, T. B., Alfarra, M. R., Williams, P. I., Bower, K., Kondo, Y., Schneider, J., Drewnick, F., Borrmann, S., Weimer, S., Demerjian, K., Salcedo, D., Cottrell, L., Griffin, R., Takami, A., Miyoshi, T., Hatakeyama, S., Shimono, A., Sun, J. Y., Zhang, Y. M., Dzepina, K., Kimmel, J. R., Sueper, D., Jayne, J. T., Herndon, S. C., Trimborn, A. M., Williams, L. R., Wood, E. C., Middlebrook, A. M., Kolb, C. E., Baltensperger, U., and Worsnop, D. R.: Evolution of organic aerosols in the atmosphere, Science, 326, 1525-1529, doi:10.1126/science.1180353, 2009.

Johnson, B., Turnbull, K., Brown, P., Burgess, R., Dorsey, J., Baran, A. J., Webster, H., Haywood, J., Cotton, R., Ulanowski, Z., 
Hesse, E., Woolley, A., and Rosenberg, P.: In situ observations of volcanic ash clouds from the FAAM aircraft during the eruption of Eyjafjallajökull in 2010, J. Geophys. Res.-Atmos., 117, D00U24, doi:10.1029/2011JD016760, 2012.

Kaye, P. H., Hirst, E., Greenaway, R. S., Ulanowski, Z., Hesse, E., DeMott, P. J., Saunders, C., and Connolly, P.: Classifying atmospheric ice crystals by spatial light scattering, Opt. Lett., 33, 1545-1547, doi:10.1364/OL.33.001545, 2008.

Kirkby, J., Curtius, J., Almeida, J., Dunne, E., Duplissy, J., Ehrhart, S., Franchin, A., Gagne, S., Ickes, L., Kurten, A., Kupc, A., Metzger, A., Riccobono, F., Rondo, L., Schobesberger, S., Tsagkogeorgas, G.,Wimmer, D., Amorim, A., Bianchi, F., Breitenlechner, M., David, A., Dommen, J., Downard, A., Ehn, M., Flagan, R. C., Haider, S., Hansel, A., Hauser, D., Jud, W., Junninen, H., Kreissl, F., Kvashin, A., Laaksonen, A., Lehtipalo, K., Lima, J., Lovejoy, E. R., Makhmutov, V., Mathot, S., Mikkila, J., Minginette, P., Mogo, S., Nieminen, T., Onnela, A., Pereira, P., Petaja, T., Schnitzhofer, R., Seinfeld, J. H., Sipila, M., Stozhkov, Y., Stratmann, F., Tome, A., Vanhanen, J., Viisanen, Y., Vrtala, A., Wagner, P. E., Walther, H., Weingartner, E., Wex, H., Winkler, P. M., Carslaw, K. S., Worsnop, D. R., Baltensperger, U., and Kulmala, M.: Role of sulphuric acid, ammonia and galactic cosmic rays in atmospheric aerosol nucleation, Nature, 476, 429-433, 2011.

Koop, T., Bookhold, J., Shiraiwa, M., and Pöschl, U.: Glass transition and phase state of organic compounds: dependency on molecular properties and implications for secondary organic aerosols in the atmosphere, Phys. Chem. Chem. Phys., 13, 19238-19255, doi:10.1039/C1CP22617G, 2011.

Kramer, J.: An integrated optical transient sensor, Circuits and Systems II: Analog and Digital Signal Processing, IEEE T. Circuits Syst. - II, 49, 612-628, doi:10.1109/TCSII.2002.807270, 2002.

Krämer, M.: HALO ice crystal spectrometer intercomparison at the AIDA-chamber: first results from the Novel Ice Experiment NIXE-CAPS, Geophys. Res. Abstr., Vol. 11, EGU General Assembly, Vienna, Austria, 2009.

Kulkarni, G., Pekour, M., Afchine, A., Murphy, D. M., and Cziczo, D. J.: Comparison of experimental and numerical studies of the performance characteristics of a pumped counterflow virtual impactor, Aerosol Sci. Tech., 45, 382-392, doi:10.1080/02786826.2010.539291, 2011.

Lance, S.: Coincidence errors in a Cloud Droplet Probe (CDP) and a Cloud and Aerosol Spectrometer (CAS), and the improved performance of a modified CDP, J. Atmos. Ocean. Tech., 29, 15321541, doi:10.1175/JTECH-D-11-00208.1, 2012.

Lawson, R. P. B., Baker, B. A., and Pilson, B. A.: In-situ measurements of microphysical properties of mid-latitude and anvil cirrus, in: Proceedings 30th International Symposium on Remote Sensing Environment, 10-14 November 2003, Honolulu, Hawaii, 707-710, 2003.

Lawson, R. P., Pilson, B., Baker, B., Mo, Q., Jensen, E., Pfister, L., and Bui, P.: Aircraft measurements of microphysical properties of subvisible cirrus in the tropical tropopause layer, Atmos. Chem. Phys., 8, 1609-1620, doi:10.5194/acp-8-1609-2008, 2008.

Macke, A., Mueller, J., and Raschke, E.: Single scattering properties of atmospheric ice crystals, J. Atmos. Sci., 53, 2813-2825, doi:10.1175/1520-0469(1996)053<2813:SSPOAI>2.0.CO;2, 1996.
Meyer, J.: Ice crystal measurements with SIMONE and CAS DPOL, PhD thesis, Julich Forschungszentrum, Wuppertal, Germany, 140 pp., 2011.

Mikhailov, E., Vlasenko, S., Martin, S. T., Koop, T., and Pöschl, U.: Amorphous and crystalline aerosol particles interacting with water vapor: conceptual framework and experimental evidence for restructuring, phase transitions and kinetic limitations, Atmos. Chem. Phys., 9, 9491-9522, doi:10.5194/acp-9-9491-2009, 2009.

Möhler, O., Field, P. R., Connolly, P., Benz, S., Saathoff, H., Schnaiter, M., Wagner, R., Cotton, R., Krämer, M., Mangold, A., and Heymsfield, A. J.: Efficiency of the deposition mode ice nucleation on mineral dust particles, Atmos. Chem. Phys., 6, 30073021, doi:10.5194/acp-6-3007-2006, 2006.

Noma, Y. and Asakawa, Y.: Biotransformation of monoterpenoids by microorganisms, insects, and mammals, in: Handbook of Essential Oils: Science, Technology, and Applications, CRC Press, Boca Raton, FL, USA, 585-736, 2010.

Notholt, J., Luo, B. P., Fueglistaler, S., Weisenstein, D., Rex, M., Lawrence, M. G., Bingemer, H., Wohltmann, I., Corti, T., Warneke, T., von Kuhlmann, R., and Peter, T.: Influence of tropospheric $\mathrm{SO}_{2}$ emissions on particle formation and the stratospheric humidity, Geophys. Res. Lett., 32, L07810, doi:10.1029/2004GL022159, 2005.

Omar, A. H., Won, J.-G., Winker, D. M., Yoon, S.-C., Dubovik, O., and McCormick, M. P.: Development of global aerosol models using cluster analysis of Aerosol Robotic Network (AERONET) measurements, J. Geophys. Res.-Atmos., 110, D10S14, doi:10.1029/2004JD004874, 2005.

Pandis, S. N., Harley, R. A., Cass, G. R., and Seinfeld, J. H.: Secondary organic aerosol formation and transport, Atmos. Environ. A-Gen., 26, 2269-2282, doi:10.1016/0960-1686(92)90358R, 1992.

Petzold, A., Esselborn, M., Weinzierl, B., Ehret, G., Ansmann, A., Müller, D., Donovan, D., van Zadelhoff, G.-J., Berthier, S., Wiegner, M., Gasteiger, J., Buras, R., Mayer, B., Lajas, D., and Wehr, T.: ICAROHS inter-comparison of aerosol retrievals and observational requirements for multi-wavelength HSRL systems, in: Proceedings of the ESA Living Planet Symposium, Bergen, Norway, ESA SP-686, December 2010, edited by: Lacoste-Francis, H., ESA Communications published and distributed by: ESA Communications, ESTEC, Noordwijk, the Netherlands, p. 102, 2010.

Renbaum-Wolff, L., Grayson, J. W., Bateman, A. P., Kuwata, M., Sellier, M., Murray, B. J., Shilling, J. E., Martin, S. T., and Bertram, A. K.: Viscosity of alpha-pinene secondary organic material and implications for particle growth and reactivity, P. Natl. Acad. Sci. USA, 110, 8014-8019, doi:10.1073/pnas.1219548110, 2013.

Robinson, E. S., Saleh, R., and Donahue, N. M.: Organic aerosol mixing observed by single particle mass spectrometry, J. Phys. Chem. A, 117, 13935-13945, doi:10.1021/jp405789t, 2013.

Rosenberg, P. D., Dean, A. R., Williams, P. I., Dorsey, J. R., Minikin, A., Pickering, M. A., and Petzold, A.: Particle sizing calibration with refractive index correction for light scattering optical particle counters and impacts upon PCASP and CDP data collected during the Fennec campaign, Atmos. Meas. Tech., 5, 1147-1163, doi:10.5194/amt-5-1147-2012, 2012. 
Schnaiter, M.: The Ice Cloud Characterisation Campaign HALO02, Geophys. Res. Abstr., Vol. 11, EGU General Assembly, Vienna, Austria, 2009.

Seber, G. A. F.: Multivariate Observations, John Wiley \& Sons, Hoboken, NJ, 1984.

Spath, H.: Cluster Dissection and Analysis: Theory, FORTRAN Programs, Examples, Halsted Press, New York, 1985.
Tajiri, T., Yamashita, K., Murakami, M., Saito, A., Kusunoki, K., Orikasa, N., and Lilie, L.: A novel adiabatic-expansion-type cloud simulation chamber, J. Meteorol. Soc. Jpn., 91, 687-704, doi:10.2151/jmsj.2013-509, 2013.

Wiberg, K. B., Wang, Y.-G., Murphy, M. J., and Vaccaro, P. H.: Temperature dependence of optical rotation: $\alpha$-pinene, $\beta$-pinene, pinane, camphene, camphor and fenchone, J. Phys. Chem. A, 108, 5559-5563, doi:10.1021/jp040085g, 2004. 